\title{
La data de l'1 de maig de 1381 en el «Libre de Fortuna e Prudència» de Bernat Metge: realitat, folklore popular, reminiscències de Dant o mer tòpic literari
}

\author{
Miquel Marco ARTigas
}

L'única obra de Bernat Metge anterior a Lo Somni que hagi estat datada amb seguretat és el Libre de Fortuna e Prudència. Metge reconeix que l'incident amb el vell vilanàs i el posterior viatge a l'altre món es produeix l'1 de maig de 1381: «Sapjats que-1 primer jorn de may/ l'any, de la nativitat santa/ de Déu, mil e trecents vuytanta/ ez un de plus, ans d'alba clara». (vv. 26-29).

La primera pregunta que hom es fa en relació a aquesta data és per què Metge és tan exacte en la datació del viatge.

En un primer estudi, Riquer va relacionar aquesta data amb seriosos problemes que Metge podria estar patint: «Jats qu-eu sia molt occupats/d'alcuns affers qui m'an portatz/ en tal perill d'on cuyt morir,/ ges per ayçò no vulh jaquir/ en lo tinter ço qu-ausiretz». (vv. 1-5)

Riquer relaciona el primer de maig amb l'estat de perill que el nostre secretari reial pateix. Diversos documents escrits al voltant d'aquesta jornada de 1381, reflecteixen les quantitats de diner que Metge va percebre del duc de Girona. Aquestes donacions, que representaven un tracte de favor en relació als altres funcionaris àulics, potser van ocasionar una situació de recel i enveja cap al nostre escrivà, motiu pel qual es sentí en perill en el moment d'escriure el seu Libre'.

A mode d'exemple, reprodueixo alguns documents que testimonien les continues quantitats que Bernat Metge rebia de la Cort:

a) 1380, 20 de març. Girona. «Item, doné a.N Bernat Metge, secretari del senyor Rey, en paga d'açò que li restava a pagar d'aquells CCC florins

1 «Los cuantiosos salarios que percibía nuestro escritor en la cancillería del duque de Gerona y las graciosas donaciones con que era frecuentemente favorecido, explican que la suerte de Bernat Metge fuera envidiable, lo que muy bien podría justificar el estado de ánimo que se transparenta en el poema». Martín de Riquer, Obras de Bernat Metge, Universidad de Barcelona, Barcelona, 1959 , pag. *31. 
d'or d'Aragó, qui a ell eren deguts, ab letra del senyor Rey, estant Duch, dada en Gerona a XX dies de març McccLxxx... C florins d'or.»

b) 1380,6 de julio. Barcelona. El infante don Juan ordena que se paguen a Bernat Metge 200 florines «per satisfactionem diversorum laboram».

c) 1380,8 de noviembre. Sant Feliu de Llobregat. El infante don Juan manda pagar a Bernat Metge 300 sueldos [...], y además le concede otros 800 graciosamente.

d) 1381, 27 de abril, Barcelona. Bernat Metge reconoce haber percibido 100 sueldos del prior de Montserrat ${ }^{2}$.

Per altra banda, el primer de maig cal inscriure'l, també, dins d'un context folklòric tradicional $i$ popular amb uns trets de caràcter màgic i fantàstic. En aquest àmbit el viatge de Metge adquireix un major verisme, en produir-se en una data on la fantasia i la màgia tenen protagonisme.

En molts pobles europeus, durant l'Edat Mitjana, se celebrava el primer de maig, la festa de l'arbre. Aquesta festa a Catalunya era força popular. Cada any, a finals d'abril, es reunien els joves de cada poble i escollien dels boscos més propers l'arbre considerat més bell, apoderant-se d'ell amb el permís del propietari o sense. El primer de maig, aquest arbre es plantava enmig de la plaça i s'ornava amb flors i cintes. Al voltant de l'arbre es ballava, s'encenien fogueres, i el poble es lliurava a l'alegria i a la disbauxa, que en ocasions era excessiva. L'origen d'alguns balls es relaciona amb el ritual de l'arbre de maig. Aquests balls, originàriament, s'empraven per implorar a les divinitats i obtenir un bon any, referit, principalment, als fruits dels arbres. Una variant d'aquesta festa era el costum que es feia a Barcelona de plantar, el primer de maig, un pi a la Casa del Canonge i en el reracor de la Catedral. Aquest costum commemorava la fundació per part del Canonge de la Seu, Bernat de Pinells, a la Casa dels Canonges, de la Pia Almoina. L'objectiu de Pinells era que les persones que no tinguessin mitjans per guanyar-se la vida, o tinguessin necessitats, sempre trobessin la taula parada ${ }^{3}$.

La Pia Almoina de la Seu de Barcelona era una institució caritativa nascuda l'any 1161 i que tenia com a finalitat donar de menjar diàriament als pobres de la ciutat. L'any 1275 , es va dotar d'un sistema administratiu que la va portar al seu màxim esplendor com a institució de caritat. Els tres centenars de pobres que menjaven cada dia, l'edifici que estatjava aquesta seu, i que subsisteix avui dia, i l'abundós arxiu de la mateixa seu, donen fe de la importància que aquesta institució assolí a Barcelona. La Pia Almoina va saber adaptar-se a les condicions canviants de la societat i a l'economia que la vida va anar adoptant

${ }^{2}$ Per a un millor coneixement d'aquests documents i d'altres de similars característiques, ibid, pp. *220-224.

3 Extret de l'obra de Joan Amades, Les diades populars catalanes, vol. II, Barcino, Barcelona, 1935; de l'obra de Luis Almerich, Tradiciones, fiestas y costumbres populares de Barcelona, Librería Millá, colección Monografías históricas de Barcelona, $n{ }^{\circ} 1$, Barcelona, 1944, i de l'article periodístic de Ramon Comas, «L'arbre de maig», publicat a La Veu de Catalunya del 16 de maig de 1897. 
des dels inicis fins al segle XIX, on es va extingir pràcticament pels efectes de les lleis acordades en aquell segle.

La relació que s'estableix entre la festa popular del primer de maig, que coincidia amb la plantada de l'arbre a la Casa del Canonge de la Pia Almoina (lloc on es convidava diàriament els pobres a menjar); entre Amiclates (paradigma de la pobresa segons la tradició i figura procedent de la Farsàlia de Lucà, personatge que s'ha relacionat amb el vell vilanàs que enganya Metge $i$ simbolitza la serenitat espiritual i la vida humil allunyada dels béns materials) i entre el Convivio de Dant (on l'autor ens convida també a un àpat, malgrat que aquest és de caràcter espiritual) podrien justificar la data que utilitza Metge per a iniciar el seu viatge a l'altre món.

Tampoc no es pot oblidar que la situació interna de la ciutat de Florència quan Dant és nomenat, junt amb altres membres del partit blanc, prior per al bimestre 15 de juny-15 d'agost, és molt turbulenta i aquesta situació tenia com a rerefons el sagnant enfrontament esdevingut l'1 de maig de 1300.

Dino Compagni (1260-1324), compatriota i amic de Dant, unit a ell pels mateixos ideals i per infortunis, relata a la seva crònica sobre les discòrdies civils entre güelfs i gibel-lins i la posterior fractura interna en el bàndol güelf entre blancs i negres i les consequiències politicosocials a la Florència del segle XIV, quin va ser el fet que va determinar l'enemistat entre el partit dels Cerchi (blancs) i el dels Donati (negres):

Como es más fácil engañar a los jóvenes que a los viejos, el diablo, acrecentador de males, se hizo de una brigada de jóvenes que encontrándose juntos la noche del primero de mayo mientras cenaban, se ensorberbecieron tanto, que pensaron ir a buscar a un grupo de los Cerchi y usar contra ellos las manos y los hierros. Esa noche, que es la renovación de la primavera, las mujeres frecuentan mucho los bailes de la comarca. Los jóvenes de los Cerchi se encontraron con la brigada de los Donati, entre los cuales estaba un sobrino de Micer Corso y de Bardellino de Bardi, Piero Spini y otros compañeros y partidarios, los cuales asaltaron la brigada de los Cerchi a mano armada. En ese asalto le cortó la nariz a Ricoverino de Cerchi, un hombre de los Donati, el cual se dice que fue Piero Spini, y se refugiaron en su casa. Ese golpe significó la destrucción de nuestra ciudad, porque se alimentó mucho el odio entre los ciudadanos. Los Cerchi no revelaron jamás quién había sido esperando poder vengarse de él. De nuevo se dividió la ciudad entre los grandes, el pueblo mediano y la plebe; y los religiosos no pudieron impedir que, de corazón, estuvieran con esos partidos, quién con uno quién con otro4.

També cal tenir present que la datació tan exacta de l'obra pot tenir com a motiu el simple ús d'un tòpic literari. Una obra d'influència com ara La Faula de Guillem de Torroella fa constar la data en què es produeix el fet que porta al protagonista a iniciar el seu viatge fantàstic: «Ço fo.l matí de Sant Johan/ Que-1

${ }^{4}$ Dino Compagni, Crónica de los blancos y los negros, traducción y estudio preliminar de José Luis Romero, Nova Biblioteca Histórica, Buenos Aires, 1948, pág, 62. 
temps fo clar e l'aura pura» (vv.4-5). El Roman de la Rose, obra també d'influència, diu que els fets van ocórrer fa uns cinc anys durant el mes de maig. I tot això sense endinsar-nos en la tradició literària medieval en relació a aquest tòpic.

Per tant, podem observar des de diferents vessants el motiu que portà Metge a datar amb exactitud la seva primera obra. Les hipòtesis presentades són força diferents. Així, la més lògica i pragmàtica relaciona la data del primer de maig amb les circumstàncies personals que envoltaven la vida cortesana del secretari reial. Unes circumstàncies, les quals posaven en perill la vida del propi autor ja que les contínues donacions rebudes per part del duc de Girona afavorien les enveges de la resta de secretaris i notaris envers Bernat Metge.

D'altra banda, la data també té reminiscències màgiques i fantàstiques unides al folklore popular, la qual cosa es relaciona molt amb el tipus de literatura on es produeix un viatge al altre món.

La hipòtesi més agosarada, no obstant, però no per això descartable a les primeres de canvi, és la que vincula la data del Libre de Fortuna e Prudència amb les desgràcies de Dant; però, cal dir en el seu favor que, provat l'interès de Metge per Dant i la seva obra i el coneixement que tenia del florentí, no podem excloure la possibilitat que la datació estigui relacionada amb l'autor de la Divina Comèdia i amb la seva situació personal.

Cal tenir en compte, també, que els topoi literaris omplen la literatura medieval i no es pot mai descartar aquesta opció, la de l'ús de la tòpica, quan tractem obres de l' Edad Mitjana. 